Hydrology and Earth System Sciences, 8(5), 923-930 (2004) C EGU

\title{
Can soil moisture be mapped onto the terrain?
}

\author{
E.M. Blyth, J. Finch, M. Robinson and P. Rosier \\ Centre for Ecology and Hydrology, Wallingford, Oxon OX10 8BB, UK \\ Email for corresponding author: emb@ceh.ac.uk
}

\begin{abstract}
Soil moisture heterogeneity has an effect on the rainfall-runoff characteristics of a landscape. The aggregate effect on the mean water balance over an area can be quantified successfully using models such as the PDM (Moore, 1986) and TOPMODEL (Beven and Kirkby, 1979). These rainfall-runoff models have been embedded in the large-scale land surface schemes used in meteorological models. However, there is also a requirement (e.g. model validation) to identify the spatial structure of the fine-scale soil moisture heterogeneity that makes up these aggregate models. In some types of landscape, this will be dictated by topography, in others by soil characteristics, or by a combination of both. A method to distribute area-average soil moisture according to the likely effect of local topography is presented and tested. The heterogeneity of the soil moisture is described by the Xinanxiang distribution (Zhao et al., 1980), commonly used to describe the natural spatial heterogeneity of the landscape. This distribution is then mapped onto the terrain using a topographic index to locate the wettest and driest areas. Soil moisture data from the Wye catchment in Wales and from the Pang catchment in Berkshire, England, are used to test the method. It is found that soil moisture data from the Wye catchment follow the topographic index reasonably well, whereas data from the quick-draining, chalky Pang catchment do not. The conclusion that topographic index is a useful indicator only in some landscapes applies equally to using this mapping method and those models that use topographic index directly.
\end{abstract}

Keywords: soil moisture, heterogeneity, topographic index, data

\section{Introduction}

Inclusion of the spatial distribution of soil moisture in largescale meteorological models (Dumenil and Todini, 1992; Wood et al., 1992) has improved the prediction of soil moisture evolution by modelling the rainfall-runoff process (Blyth, 2002). The most readily used method of representing the heterogeneity of soil moisture in a landscape is to assume the soil moisture follows the Xinanxiang statistical relationship (Zhao et al., 1980) to describe the natural heterogeneity of the landscape, allowing some areas to be saturated while other areas remain dry. This assumption is used to calculate surface runoff generated during a period of rainfall in land surface models such as PDM (Probability Distributed Model, Moore, 1986) VIC (Variable Infiltration Capacity, Wood et al., 1992) and Arno (Dumenil and Todini, 1992). The methods have been used successfully to model the overall water balance of an area (which is what they were designed for) (Lohmann et al., 1998).
In these meteorological models, soil moisture is a state variable that is calculated as it affects other meteorological outputs, such as air temperature and moisture flux into the atmosphere. However, there is a requirement of meteorological models to output useful estimates of soil moisture for use in other applications such as hydrology, flooding, agriculture and soil strength. Thus, there is an increasing need to validate the modelled soil moisture values with observations.

Soil moisture represents a particular challenge for model validation as direct observations are made at a local scale and soil moisture displays significant spatial heterogeneity due to soil characteristics and topography. Remotely-sensed information about the surface can be at a finer scale than the meteorological models (Pellenq et al., 2003), and so an estimate of how the surface fields of soil moisture (and therefore temperature) vary within a model grid is required. Thus, although the effects of soil moisture on runoff and 
evaporation, for instance, can be regionalised using nonpositional aggregation models and theories, the position of the different values of soil moisture matter when trying to validate the large scale model. Disaggregation of model outputs is also needed for some impacts modelling. For instance, the location of extremes of soil moisture may be required for military and agricultural purposes. The changes in soil moisture of a particular location may not relate directly with the mean modelled soil moisture and a relative mapping function may be needed to put it in context. All of these are reasons to disaggregate the soil moisture. In the recent paper by Pellenq et al. (2003), the information on the topographic index and soil depth and TOPMODEL were used successfully to disaggregate the soil moisture. They stated specifically that they used TOPMODEL so that they could disaggregate the spatial distribution of soil moisture. However, it is proposed in this paper that the full TOPMODEL approach does not need to be used to achieve this kind of spatial disaggregation. Instead, a method is proposed which maps the non-positional distribution of soil moisture used in the PDM, VIC and Arno models onto the terrain using the topographic index only. Observed distributed soil moisture data over two contrasting catchments are then used to check whether the method is valid. The catchments are the Wye catchment in Wales and the Pang in Berkshire. Some large-scale rainfall-runoff models use topography directly in their formulation (Gedney and Cox, 2004; Steiglitz et al., 1997) so they do not need this mapping procedure. However, the validation procedures are still valid for these models.

\section{Method}

The Xinanxiang distribution describes the natural heterogeneity of a landscape, but has no positional information. The distribution is, therefore, mapped onto the distribution of topographic index by area: for example, the soil moisture in the wettest $10 \%$ area of the landscape is assumed to lie in the lowest $10 \%$ by area of topographic index (see Fig. 1). The technicalities of the method are laid out below.

\section{THE XINANXIANG DISTRIBUTION}

The Xinanxiang distribution (Zhao et al., 1980) is a cumulative density function, $\mathrm{F}\left(\mathrm{c}_{\mathrm{i}}\right)$, of the storage capacity, $c_{i}$, across a basin, defined as follows:

$$
F\left(c_{i}\right)=1-\left(1-\frac{c_{i}}{c_{m}}\right)^{b}
$$

where $b$ is a shape parameter, $c_{m}$ is the maximum storage capacity $\left(=\theta_{\mathrm{s}}(1+\mathrm{b})\right)$ and $\theta_{\mathrm{s}}$ is the saturated soil moisture content $\left(\mathrm{m}^{3} \mathrm{~m}^{-3}\right)$. The area of the basin, $A_{i}$, with a storage capacity up to a value of $c_{i}$ is

$$
A_{i}=F\left(c_{i}\right) \cdot A
$$

where $A$ is the area of the whole basin.

The theory has been extended by defining a Wetness Index $(W I$ ), ranging from 0 and 1 ; it is the fractional area of the basin from the wettest point (zero storage capacity) to a capacity of $\mathrm{c}_{W r}$. The value of $W I$ is calculated from the

\section{A typical catchment}

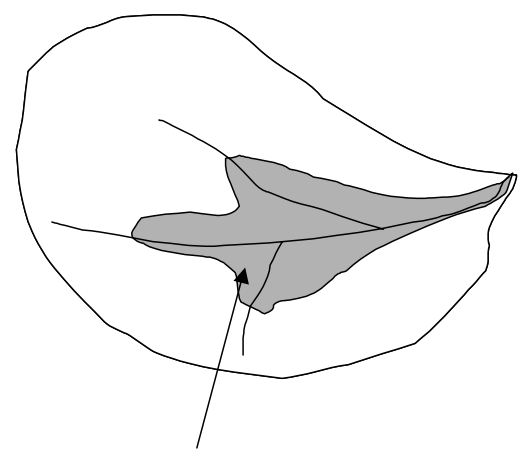

Area of highest Topographic Index assumed to be wettest

\section{$\underline{\text { Schematic diagram of distribution method }}$}

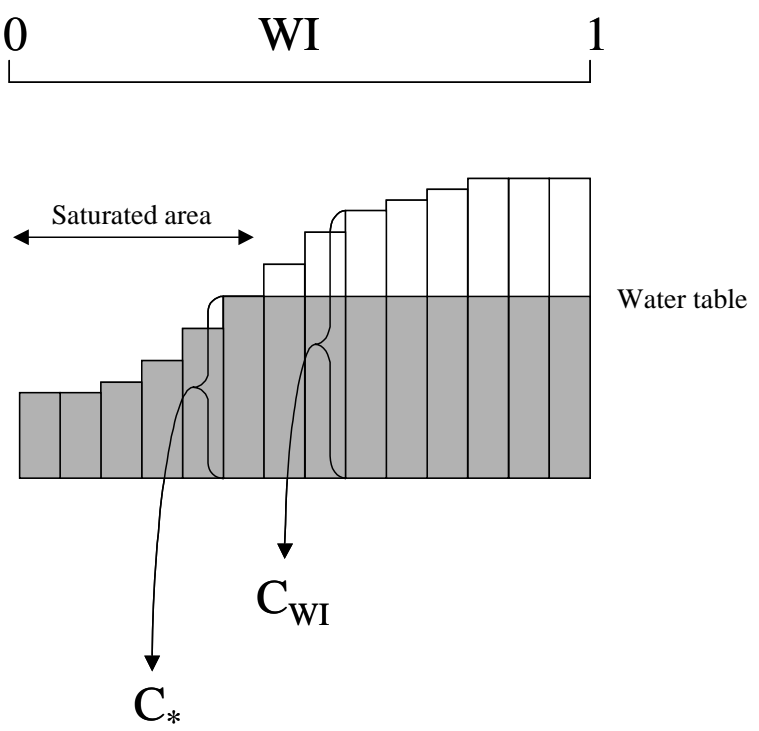


cumulative density function $F(c)$ as follows:

$$
W I=1-\left(1-\frac{c_{W I}}{c_{m}}\right)^{b}
$$

Use is made of the relationship between the critical storage value, $c_{*}$, and the mean soil moisture, $\langle\theta>$. The critical storage is the largest value of storage that is full. All stores smaller than this are also full.

$$
c_{*}=c_{m}\left(1-\left(1-\frac{<\theta>}{\theta_{s}}\right)^{\frac{1}{1+b}}\right)
$$

Therefore, the ratio of the size of the critical storage (which is saturated), $\mathrm{c}_{*}$ and $c_{W I}$ will give the unsaturated value of soil moisture at the point $W I, \theta_{W I}$. The theory is shown graphically in Fig. 1.

$$
\theta_{W I}=\theta_{s} \frac{1-\left(1-\frac{\theta}{\theta_{s}}\right)^{\frac{1}{1+b}}}{1-(1-W I)^{1 / b}}
$$

where $\theta_{W I}$ is always less than or equal to $\theta_{s}$.

\section{TOPOGRAPHIC INDEX}

A basin can be analysed to give a map of topographic index. The topographic index, TI, used here is the ratio of the log of the area (a) that drains to the point, divided by the tangent of the slope (b) of that point. It is an indication of how wet that point would be relative to the rest of the basin (Beven and Kirkby, 1979) as it relates inflows (=f (contributing area)) and outflows (=f(slope)). Mathematically, it is defined as follows:

$$
T I=\ln (a) / \tan (b)
$$

The topographic indices of a basin can be presented as a spatial map (see for instance Figs. 2 and 3).

\section{XINANXIANG TO TOPOGRAPHIC INDEX}

Bell and Moore (1998) demonstrate the link between the Xinanxiang distribution and the topographic index. To use this link, the Xinanxiang distribution of the soil moisture is distributed across the terrain as follows. The distribution is split up into 10 bins of equal areas of increasing wetness. This is done by setting WI to $0.1,0.2$ etc to 1.0 in Eqn. 1.10 topographic indices are then calculated which represent the basin split into 10 areas of equal size but with increasing values of topographic index. The mapping for the two example catchments is shown in Table 1. The values of soil moisture calculated by the Xinanxiang distribution in the

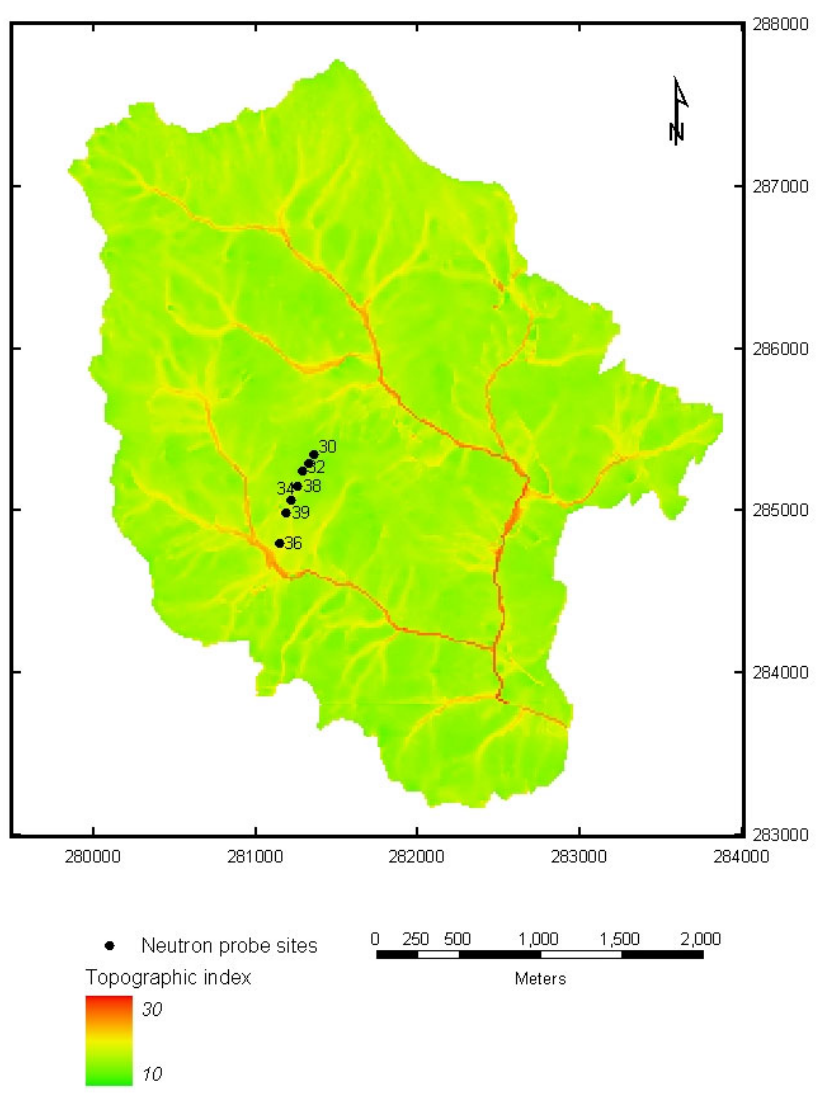

Fig. 2. Topographic index of Wye catchment

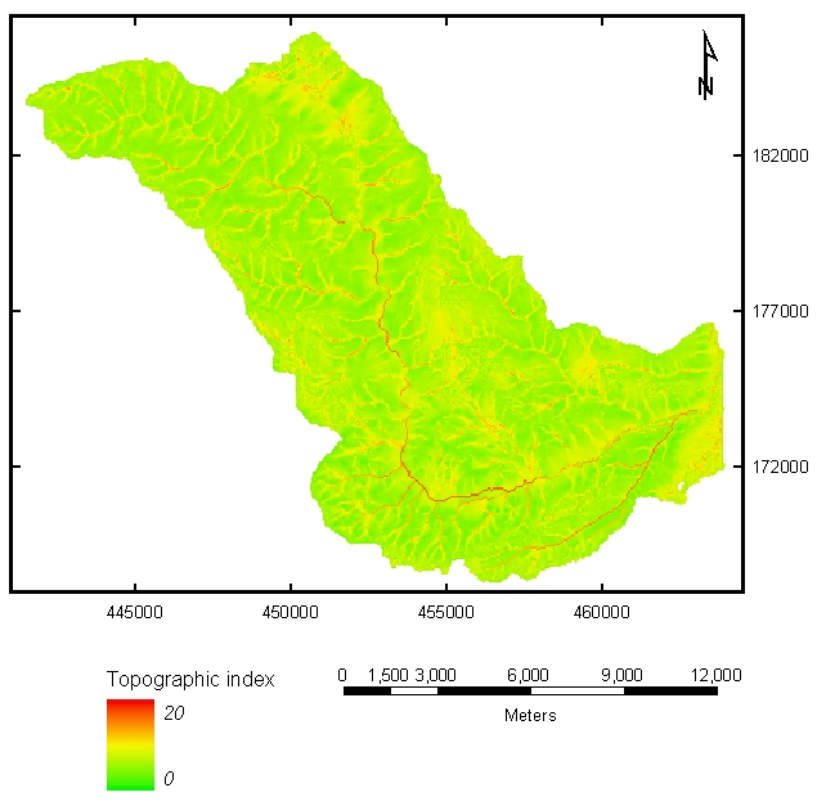

Fig. 3. Topographic index of Pang catchment 
Table 1. Distributions of WI and the equivalent value of topographic index (TI) for the Wye and Pang catchments.

\begin{tabular}{lcc}
\hline$W I$ & TIfor Wye & TIfor Pang \\
\hline 1.1 & 2.47 & 11.90 \\
0.2 & 4.19 & 13.73 \\
0.3 & 5.90 & 15.56 \\
0.4 & 7.62 & 17.39 \\
0.5 & 9.34 & 19.22 \\
0.6 & 11.05 & 21.05 \\
0.7 & 12.77 & 22.88 \\
0.8 & 14.49 & 24.71 \\
0.9 & 16.20 & 26.54 \\
1.0 & 17.92 & 28.37 \\
\hline
\end{tabular}

10 bins are then allocated a value of topographic index and can then be mapped back onto the terrain.

\section{Application and validation}

The theory was tested in two catchments in the UK where a spatial distribution of soil measurements was available: the Pang catchment in south-east England and the Upper Wye in mid-Wales.

\section{CATCHMENT DESCRIPTIONS}

Wye: This upland catchment has an altitude range of 415 to $520 \mathrm{~m}$ AOD. The valley bottom soil is Ynys series peaty gley, mid-slope is a brown podzolic soil (Manod) and the upslope is Hiraethog (stagnopodzol). The long term annual average rainfall is $2500 \mathrm{~mm}$.

Pang: The catchment of the river Pang is located on the Berkshire Downs in southern England. The geology of the catchment is dominated by the Chalk, which occupies about $85 \%$ of the area (Finch, 2000). The rest of the area consists of low permeability clay and alluvium overlying the Chalk, mainly in the south. It is predominantly a rural catchment, altitude range $40-230 \mathrm{~m}$, with the land cover dominated by cereal crops and grassland.

\section{OBTAINING THE TOPOGRAPHIC INDICES}

The spatial distribution of the topographic index for the Upper Wye and Pang catchments has been calculated from a digital terrain model (DTM). The procedure uses a multidirectional flow routing to identify the likely flow paths of the water which can then be used to calculate the accumulated flow to each cell $(a)$. The topographic slope of each cell $(b)$ is calculated from the DTM and, thus, the topographic index can be calculated for each cell. The spatial resolution of the resulting data set is the same as that of the DTM: $15 \mathrm{~m}$ in the case of the Upper Wye catchment and 50 $\mathrm{m}$ in the case of the Pang. Figures 2 and 3 shows the maps of topographic index for the Upper Wye and the Pang catchments respectively.

\section{SOIL MOISTURE OBSERVATIONS}

Wye: A transect of neutron probe (Bell, 1976) access tubes was installed down a slope in the Cyff sub-catchment of the Wye. All the tubes are under short grass and were installed through the depth of the soil zone of active moisture changes - i.e. down to bedrock or to a very low permeability horizon. Depths ranged between $45 \mathrm{~cm}$ and $75 \mathrm{~cm}$. Spacing of tubes is about $100 \mathrm{~m}$. The positions of the measurements are shown in Fig. 2. Figure 4 shows the soil moisture for the year 1976 which was a dry year (annual rainfall 1750 $\mathrm{mm}$ ). This year is chosen for this study as it shows more seasonal variation than other years. The legend shows the value of $W I$ for each location used in the analysis.

Pang: Soil moisture measurements have been made at three locations on the Chalk, in a straight line parallel to the direction of the topographic slope, with one site near the valley bottom, another near the top and the third midway between. Measurements at these sites were made using a neutron probe as described by Bell (1987). Readings were

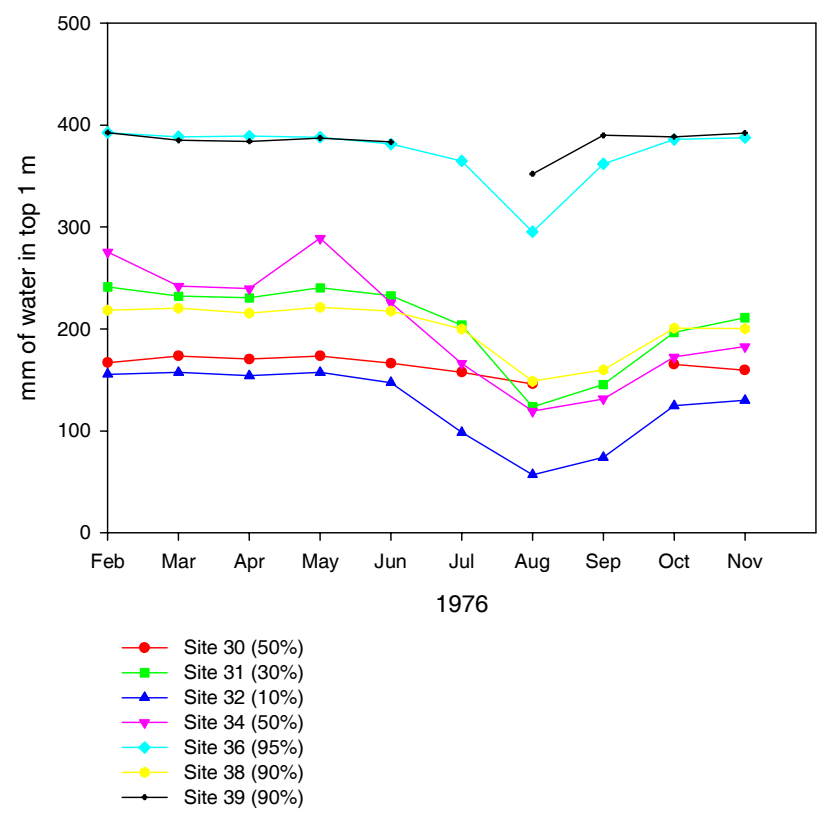

Fig. 4. Time series of measured soil moisture in the Wye $(\%$ in legend is $\mathrm{WI}$ ) 


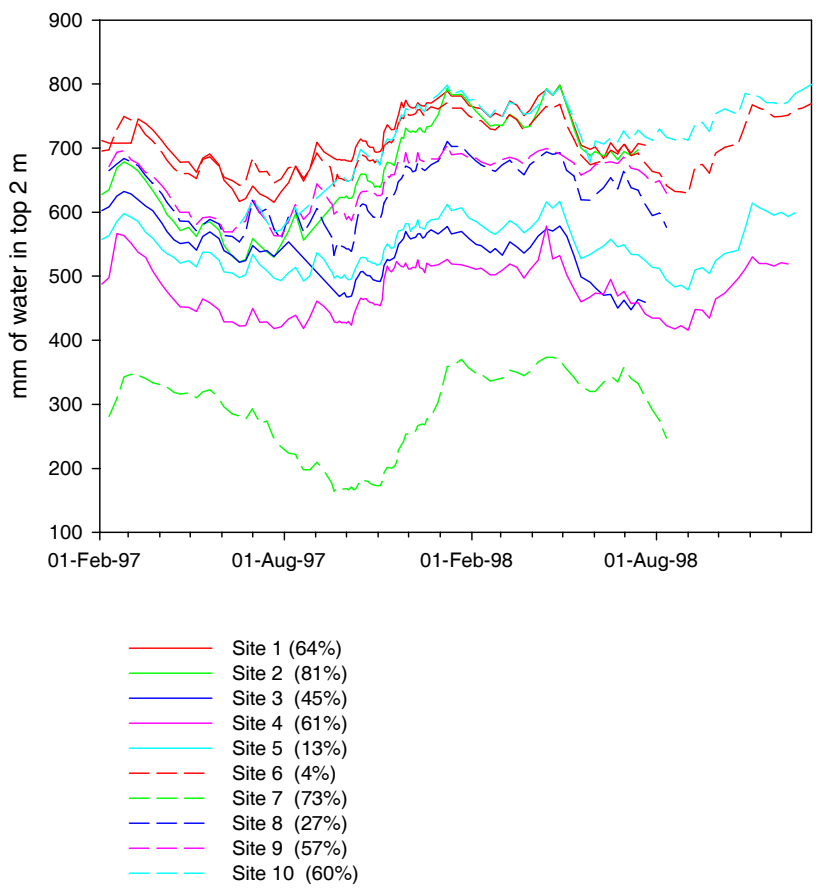

Fig. 5. Time series of measure soil moisture in the Pang $(\%$ in legend is $\mathrm{WI}$ )

taken once weekly down to a depth of $2 \mathrm{~m}$, at intervals of $0.1 \mathrm{~m}$, beginning in February 1997 and ending in July 1998. From October to December 1997, the frequency of measurements was increased to three times a week. Figure 5 shows the observed soil moistures with the legend displaying the values of $W I$.

\section{APPLYING THE METHODOLOGY}

Wye: A typical wet value of mean soil moisture $\left(0.2 \mathrm{~m}^{3} \mathrm{~m}^{-3}\right)$ and a typical dry value $\left(0.3 \mathrm{~m}^{3} \mathrm{~m}^{-3}\right)$ were taken from the observations (Fig. 4) and then distributed using the Xinanxiang distribution into the 10 bins: the wettest $10 \%$ through to the driest $10 \%$. Typical values of $\theta_{s}$ and $b$ are used: $\theta_{s}$ (which does not vary much between soils) is taken to be $0.45 \mathrm{~m}^{3} \mathrm{~m}^{-3}$, and $b$ is taken as 1 .

The values in the 10 bins were then each allocated a value of topographic index according to the method described above and shown in Table 1; this was then used to create a wet distribution and a dry distribution across the catchment. Figures 6 and 7 show these distributions.

Pang: A similar exercise was carried out with the Pang catchment. A typical 'dry' value of $0.15 \mathrm{~m}^{3} \mathrm{~m}^{-3}$ and a typical 'wet' value $0.34 \mathrm{~m}^{3} \mathrm{~m}^{-3}$ were taken from observations (see Fig. 5) and used to create Figs. 8 and 9 which show the dry and wet distributions for this catchment.
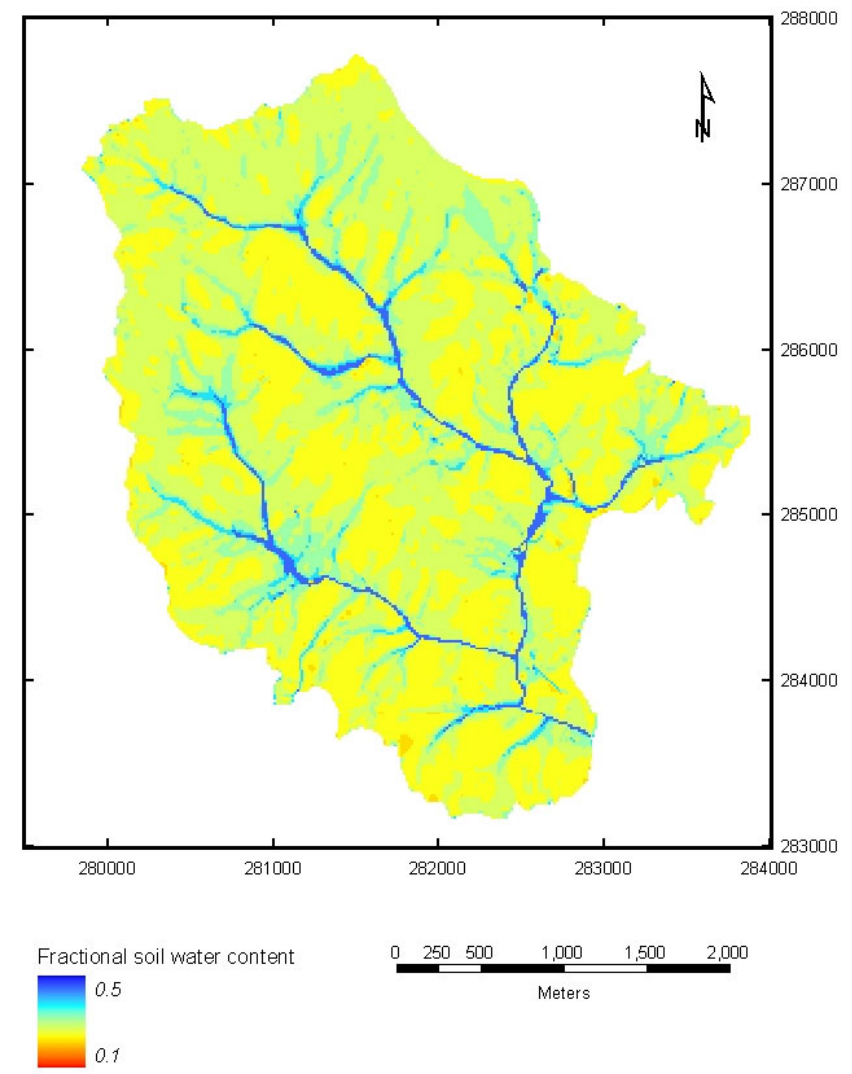

Fig. 6. Distribution of soil moisture for wet case in Wye

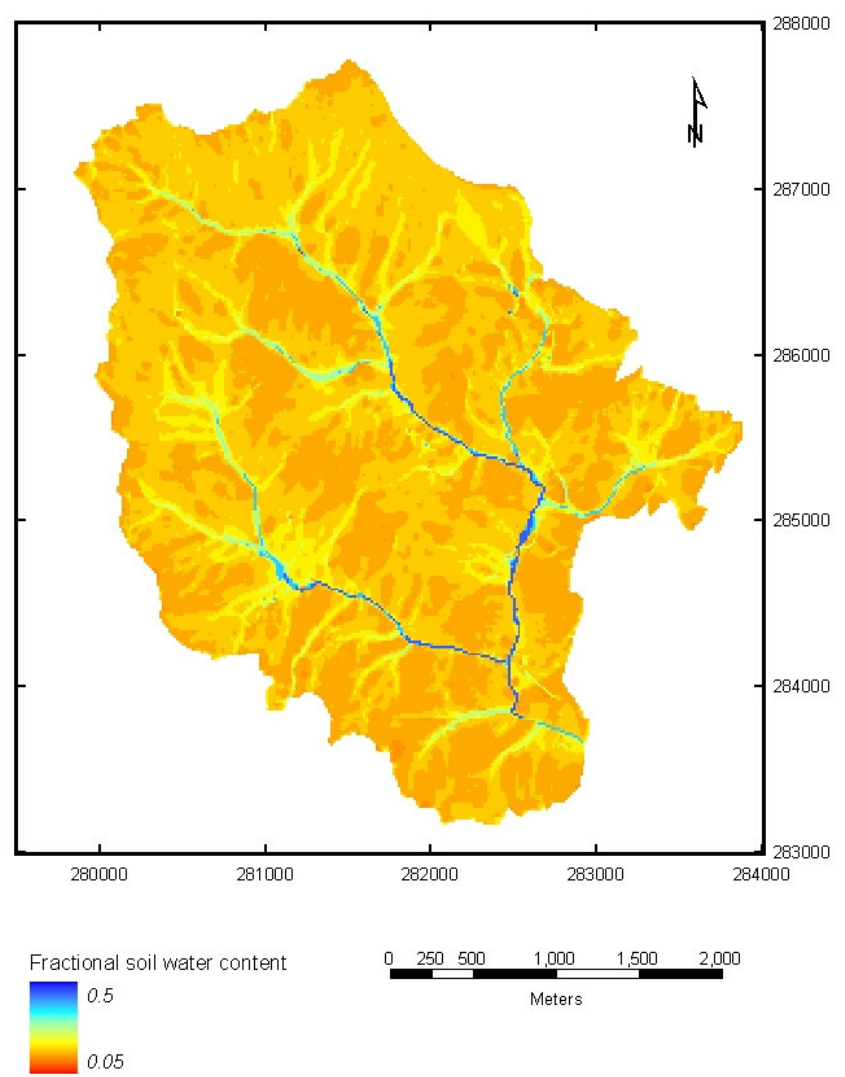

Fig. 7. Distribution of soil moisture for dry case in Wye 

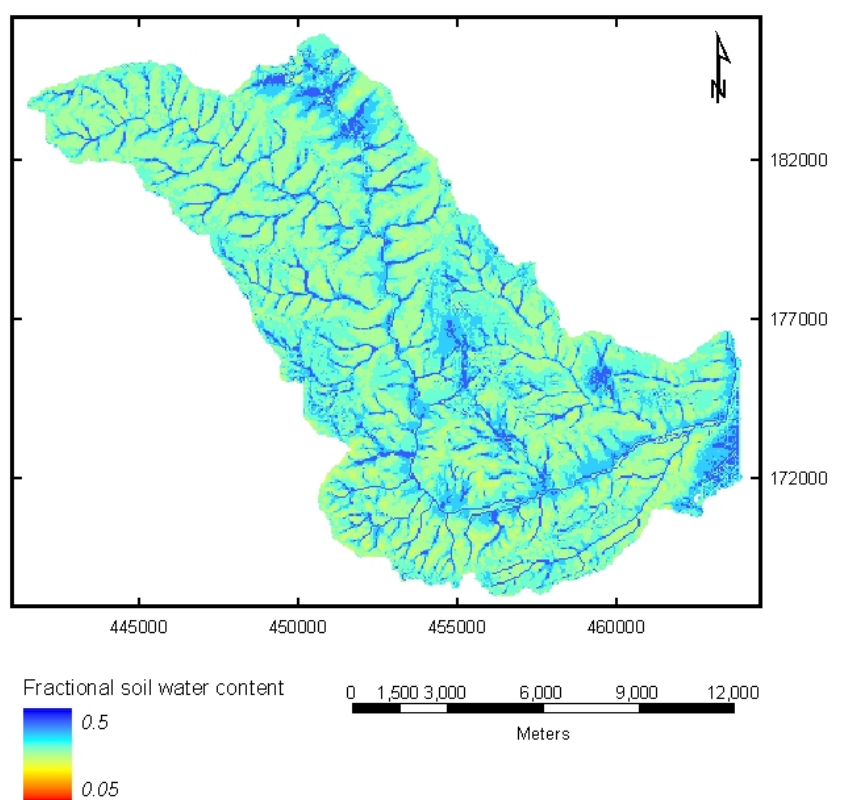

Fig. 8. Distribution of soil moisture for wet case in Pang
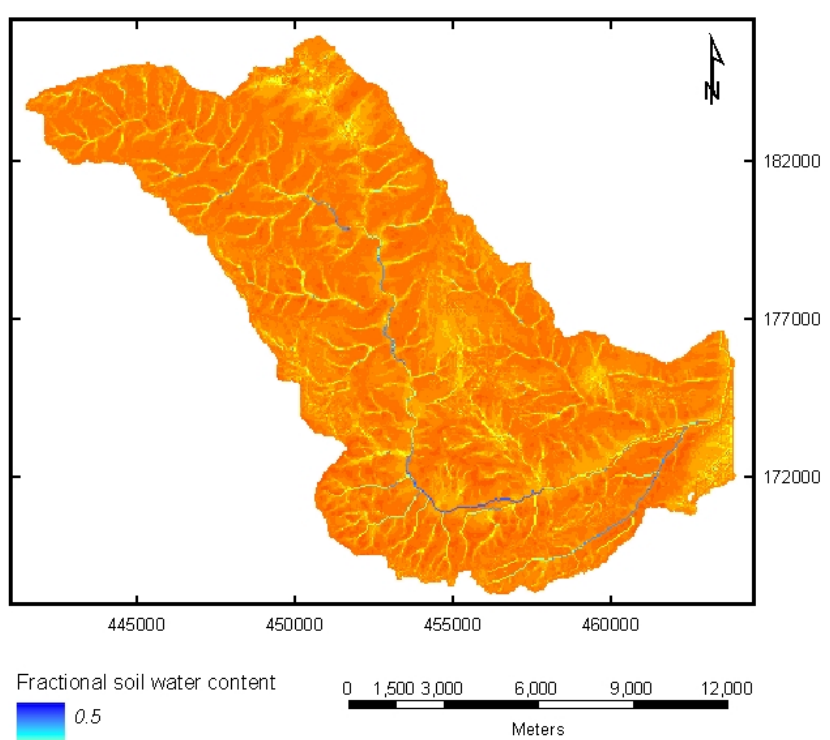

0.05

Fig. 9. Distribution of soil moisture for dry case in Pang

\section{VALIDATION OF THE METHOD}

Wye: The topographic index of the locations where the measurements were taken was used to compare the 'predicted' soil moisture with that observed, using the methodology described above. Comparing the value of the topographic index of the location according to Fig. 2 with the topographic index vs. Wetness Index in Table 1, gives the relevant value of $W I$ to be applied in Eqn. 1.

The legend shows the values of $W I$ for each location. To compare the modelled distribution with that observed, a value for the mean soil moisture was necessary - a volumeaverage rather than an area-average. Since each WI category represents a different storage capacity, the average soil moisture is calculated by weighting the observed values of soil moisture with the equivalent value of $c_{W I}$ multiplied by the area of which it is representative. Using this method, the average soil moisture for March was $0.2165 \mathrm{~m}^{3} \mathrm{~m}^{-3}$ and the average soil moisture for August was $0.1247 \mathrm{~m}^{3} \mathrm{~m}^{-3}$. Figure 10 displays the theoretical distribution of soil moisture compared to the observed values.

The predicted distribution is remarkably similar to that observed. The outliers may be due to a difference in soil porosity that has not been taken into consideration, as data were not readily available.

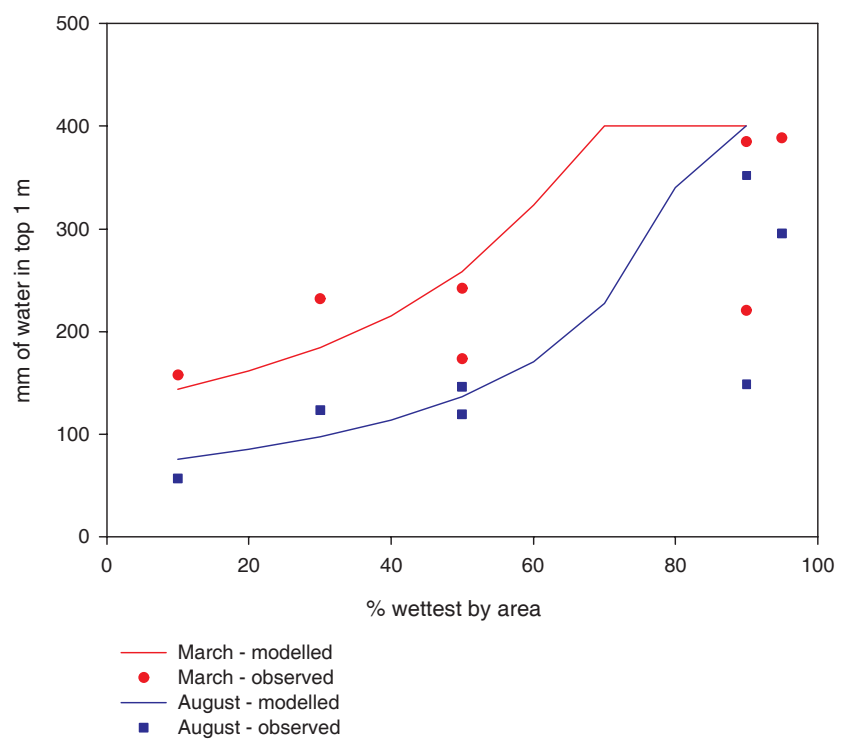

Fig. 10. Comparison of modelled and observed soil moisture for the Wye

Pang: Typical dry and wet observed values of $0.15 \mathrm{~m}^{3} \mathrm{~m}^{-3}$ and $0.35 \mathrm{~m}^{3} \mathrm{~m}^{-3}$ respectively were taken from the observed soil moisture (Fig. 5). The exact values are not important for this analysis since it is the variation with topography that is of interest.

Figure 11 shows the distributions with respect to the $W I$ for March and August for the modelled Xinanxiang distribution and the actual measurements..

There is very little correlation between the observed and modelled soil moisture in this case, probably because the catchment is predominantly chalk with high vertical transmissivity; soil water can travel vertically downwards 


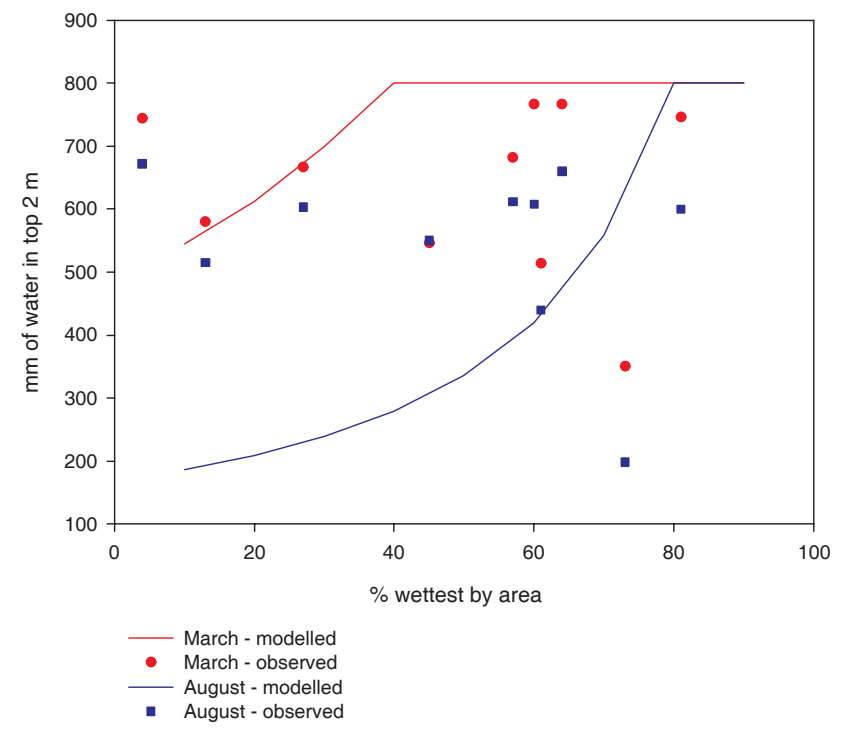

Fig. 11. Comparison of modelled and observed soil moisture for the Pang

with little to impede it. Topography will be apparent in the surface soil moisture distribution only if the water travels laterally; this will require the vertical impedance to route the water sideways down the hillside.

In an attempt to identify some signal from the terrain (topography or soil type) to explain the soil moisture variation, the porosity of the soils was studied. (Table 2 ) To include the porosity in the topographic index, albeit crudely, it was hypothesised that it altered the topographic index as follows (Hillel, 1982) so that a higher porosity results in a drier soil.

$$
T I_{p}=T I+\ln \left(1 / p^{2}\right)
$$

where $T I_{p}$ is Topographic index with porosity, $T I$ is the Topographic index and $p$ is the porosity.

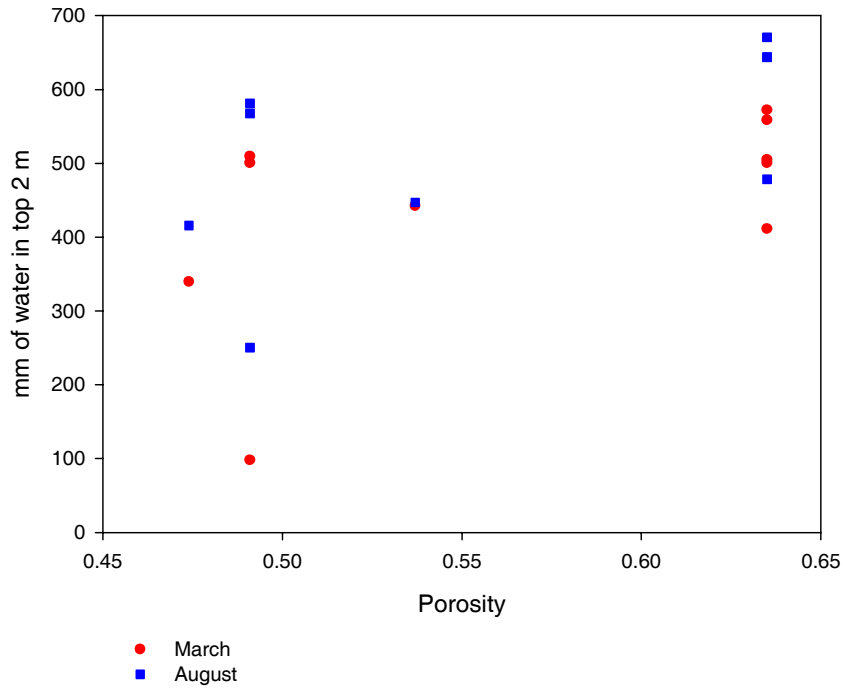

Fig. 12. Observed soil moisture plotted against porosity for the Pang

However, no correlation was found between the variation in soil moisture and the porosity (Fig. 12). A highly porous soil should result in lower soil moisture but there is no evidence of any such relationship.

\section{Conclusions and recommendations}

This paper proposes that the non-positional distributions of soil moisture represented in the widely-used PDM, VIC and Arno models can be disaggregated across a landscape using the Topographic Index. The method proved effective in identifying the location and extent of soil moisture variation at scales below that of the model grid using sub-grid scale information about topography for one of the catchments (the Wye). However, the catchment of the Pang displays no relationship between soil moisture and topography or porosity. This is probably because it is a chalky catchment

Table 2. Soil types and porosity for soils in the Pang catchment

\begin{tabular}{|c|c|c|c|c|c|}
\hline Site No. & Land Cover & Soil Association & Porosity & Topographic Index & Topographic Index with porosity \\
\hline 1 & Spring barley & Andover & 0.635 & 12.15 & 13.96 \\
\hline 2 & Spring barley & Andover & 0.635 & 13.22 & 14.13 \\
\hline 3 & Spring barley & Coombe & 0.537 & 11.43 & 12.67 \\
\hline 4 & Grass ley & Hornbeam & 0.474 & 12.04 & 13.53 \\
\hline 5 & Grass ley & Andover & 0.635 & 10.39 & 11.30 \\
\hline 6 & Permanent grass & Andover & 0.635 & 9.94 & 10.85 \\
\hline 7 & Permanent grass & Wickham & 0.491 & 12.67 & 14.09 \\
\hline 8 & Permanent grass & Wickham & 0.491 & 10.87 & 12.29 \\
\hline 9 & Deciduous tress & Wickham & 0.491 & 11.83 & 13.25 \\
\hline 10 & Cereals & Andover & 0.635 & 11.98 & 12.89 \\
\hline
\end{tabular}


where vertical drainage is high and so topographic effects are not evident at the surface. Therefore it must be stressed that Figs. 8 and 9 are entirely bogus! The spatial patterns of soil moisture shown in these maps bear no relation to what would be found on the ground. In contrast, for the Wye catchment, Figs. 6 and 7 are likely to be reasonable estimates of the patterns of soil moisture

The method was designed to enable testing for extremes as well as to determine mean soil moisture, to distribute the soil moisture across the terrain, to identify where extremes might lie and to map the soil moisture within the grids for validation with remotely-sensed data. In this it has been successful in a catchment where the methodology was applicable. Hence, guidelines of where the method is applicable should be drawn up and more monitoring of distributed soil moisture is required.

\section{Acknowledgements}

This work was funded by the Met Support Group of the Ministry of Defence

\section{References}

Bell, V.A. and Moore, R.J., 1998. A grid-based distributed flood forecasting model for use with weather radar data: Part 1. Formulation. Hydrol. Earth Syst. Sci., 2, 265-281.

Beven, K.J. and Kirkby, M.J., 1979. A physically based variable contributing area model of basin hydrology. Hydrol. Sci. Bull. 24, 43-54

Blyth, E.M., 2002. Modelling soil moisture for a grassland and a woodland site in south-east England. Hydrol. Earth Syst. Sci., 6, 39-47.
Dumenil, L. and Todini, E., 1992. A rainfall-runoff scheme for use in the Hamburg climate model. In: Advances in theoretical hydrology - a tribute to James Dooge, J.P.O'Kane (Ed.), Elsevier, Amsterdam, The Netherlands. 129-157

Finch, J.W., 2000. Observations and modeling of the soil moisture deficits developed under grass and deciduous woodland - the implications for water resources. J. Chart. Inst. Water Eng. Manage., 14, 371-376.

Gedney, N. and Cox, P.M., 2004. The sensitivity of global climate model simulations to the representation of soil moisture heterogeneity. J. Hydrometeorol., 4, 1265-1275.

Hillel, O., 1982. Introduction to soil physics. Academic Press. 370pp.

Lohmann, D., Lettenmaier, D.P., Liang, X., Wood, E.F., Boone, A., Chang, S., Chen, F., Dai, Y., Desborough, C., Dickenson, R.E., Duan, Q., Ek, M., Gusev, Y.M., Habets, F., Irannejad, P., Koster, R., Mitchell, K.E., Nasonova, O.N., Noilhan, J., Schaake, J., Schlosser, A., Shao, Y., Shmakin, A.B., Verseghy, D., Warrach, K., Wetzel, P., Xue, Y., Yang, Z.-L. and Zeng, Q., 1998. The project for Intercomparison of Land-surface paramerization Schemes (PILPS) phase 2@ Red-Arkansas River basin experiment: 3. Spatial and temporal analysis of water fluxes. Global Planet. Change, 19, 161-179.

Moore, R.J., 1986. Advances in real-time flood forecasting practice. In: Symposium on Flood Warning Systems, Inst. Water Eng. Scientists, London, UK. 23pp.

Pellenq, J., Kalma, J., Boulet, G., Saulnier, G.-M., Wooldridge, S., Kerr, Y. and Chehbouni, A., 2003. A disaggregation scheme for soil moisture based on topography and soil depth. J. Hydrol., 276, 112-127.

Steiglitz, M., Rind, D., Famiglietti, J. and Rosenzweig, C., 1997. An efficient approach to modeling the topographic control of surface heterogeneity for regional and global climate modeling. J. Climate, 10, 118-137.

Wood, E.F. Lettenmaier, D.P. and Zartarian, V.G., 1992. A land surface hydrology parameterization with sub grid variability for general circulation models. J. Geophys. Res. 97, 2717-2728.

Zhao, R.J., Zuang, Y., Fang, L.R., Lin, X.R. and Zhang, Q.S., 1980. The Xinanjiang model. IAHS Publ. no. 129, 351-356. 